\title{
Enhancement of Solar Cell Modeling with MPPT Command Practice with an Electronic Edge Filter
}

\author{
Said Saad \\ Faculty of Sciences of Monastir \\ University of Monastir \\ Monastir, Tunisia \\ said.saad@,fst.rnu.tn
}

\begin{abstract}
A new photovoltaic cell modeling based on an electronically tunable edge filter is presented in this paper. The new model is subjected to temperature, illumination, and resistance variations. In addition, an MPPT (Maximum Power Point Tracker) command was exposed with a calculation algorithm based on a microcontroller card that used the behavior of an electronically tunable edge filter. The results confirm those published in the literature, showing the influence of the position of the leakage variation in our model, which can give more power. The simulation results show that the proposed command is efficient to determine the MPP point.
\end{abstract}

Keywords-photovoltaic cell; illumination; MPPT; calculation algorithm; electronic tunable efge filter

\section{INTRODUCTION}

Today, renewable energies, such as photovoltaic, wind, or hydraulic energy appear to be inexhaustible and easily exploitable. If we take the example of solar energy, an area of $145000 \mathrm{~km}^{2}$ (4\% of the arid deserts surface) of photovoltaic (PV) panels would be sufficient to cover the global energy needs [1]. Moreover, the enhancement of the efficiency of the PVs and the design and the implementation of PV systems pose challenges to builders, scientists, and researchers [2]. For a PV installation, the variations of illumination, temperature, and in load charge cause a degradation of the power supplied by the PV generator. In addition, the design of a PV cell may also have a negative effect on the performance and the results delivered to the load charge [3], that's why a new model of PV cell is proposed in this paper where a leakage resistance is inserted in series with the diode of the cell. The purpose is to demonstrate that when we minimize the leakage effect in construction we can improve the current delivered to the charge. A solar cell presents nonlinear characteristics [4]. In order to extract the maximum power at each instant from the solar cell terminals and transfer it to the load, an adaptation stage is used between the solar cell and the load [5]. However, in order to find the Maximum Power Point (MPP) point we use algorithms and commands. Several MPP tracking techniques have been developed. These approaches can be divided into smart and classical schemes. In the first scheme category, we find ripple-based extremum seeking control [6], Neural Networks [7], dissimilation particle swarm optimization [8], and the Takagi-Sugeno fuzzy model [9]. In the second category, we have the Perturb \& Observe $(\mathrm{P} \& \mathrm{O})[10]$, the effect of the DC/DC circuit voltage converter [12], and the Incremental Conductance Perturbation [13] methods.

The method of Ripple-Based Extremum seeking is fast, but the current control is less stable than the voltage control [6]. The approach of Neural Networks has proved to be very efficient and accurate, but complex [7]. The method of particle swarm optimization gives good results, however it is complex because it is based on neural networks. The fuzzy method can directly drive the system to the MPP without searching the MPP and measuring illumination [9], but it is more complicated and uses feedback in the calculations. For the approaches of $\mathrm{P} \& \mathrm{O}$ and the incremental conductance perturbation, the reasoning is the same and it is simple, also the results are the same with a difference of $0.13 \%$ in dynamic conditions and as low as $0.02 \%$ in static conditions [10]. Also the methods that use the P\&O suffer from oscillations which we always want to minimize. The method of effect of the $\mathrm{DC} / \mathrm{DC}$ circuit voltage converter is practical [11], and may be unstable $[12,14]$.

All the presented approaches and methods aim to advance the PV system efficiency. However, they suffer from certain stability problems, especially in rapid climate changes. In this paper, we researched a PV generator cell that works longer under the optimum conditions. Furthermore, the implementation of the calculation algorithm that finds the MPPT is presented and investigated. This method is based on an electronic card, and to the best of our knowledge, has not been presented before. The digital controller in the card is realized by a microcontroller-based system where the PV cell and the card are simulated in MATLAB Simulink and Proteus ISIS. The obtained results are clearly shown and discussed.

\section{SOLAR CELL MODELING}

PV solar energy comes from the direct transformation of a part of solar radiation to electrical energy. The responsible element of this transformation is the PV cell which gives a DC current. The generated voltage can vary between $0.3 \mathrm{~V}$ and $0.7 \mathrm{~V}$ depending on the material used and its arrangement as well as the temperature of the cell and its age [15]. Furthermore, the energy efficiency performance achieved industrially is 13 to $14 \%$ for cells based on monocrystalline silicon, 11 to $12 \%$ for polycrystalline silicon, and 7 to $8 \%$ for amorphous silicon in thin films [16]. The general model of a 
PV cell behaves equivalently to a current source shunted by a diode. The model is completed by a series resistor $R_{s}$ due to the contribution of the base resistors and the junction front and back with front contacts and a shunt parallel resistor, $\mathrm{R}_{\mathrm{p}}$, which comes from the metal contacts and the leakage resistors on the periphery of the PV cell [17]. Figure 1 shows this behavior and Table I gives the parameters of our resistance components.

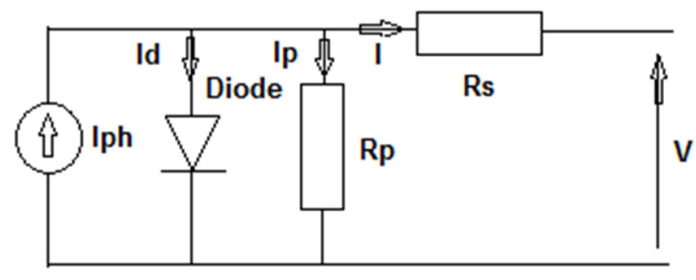

Fig. 1. Model of the PV cell.

TABLE I. RESISTANCE COMPONENT VALUES OF THE PV CELL MODEL

\begin{tabular}{|c|c|}
\hline Component & Value \\
\hline $\mathrm{R}_{\mathrm{s}}$ & $0.01 \Omega$ \\
\hline $\mathrm{R}_{\mathrm{p}}$ & $10 \Omega$ \\
\hline
\end{tabular}

The mathematical model for the current-voltage characteristic of a PV cell is given by [17]:

$$
I_{p v}=I_{p h}-I_{s}\left(e^{\frac{v_{p v}+I_{p v} \cdot R_{s}}{V_{t} \cdot n}}-1\right)-\frac{v_{p v}+I_{p v} \cdot R_{s}}{R_{p}}
$$

where $\mathrm{I}_{\mathrm{pv}}$ represents the current supplied by the cell when it operates as a generator, $\mathrm{I}_{\mathrm{ph}}$ represents the photocurrent of the cell depending on illumination and temperature, $\mathrm{I}_{\mathrm{s}}$ represents the saturation current, $\mathrm{V}_{\mathrm{pv}}$ represents the voltage across the cell, and $V_{t}=\frac{K \cdot T_{c}}{q}$ represents the thermodynamic potential with $\mathrm{K}$ being the Boltzmann's constant, $\mathrm{T}_{\mathrm{c}}$ the effective temperature of the cells in Kelvin, $\mathrm{q}$ is the electron charge, $\mathrm{n}$ represents the ideality factor of the junction, $R_{p}$ represents the shunt resistance that characterizes the leakage currents, and $R_{s}$ represents the serial resistance of various contact and connection resistances

On the other hand, we can characterize the PV cell by a current $I_{c c}$ that represents the highest current that a cell can deliver. It is a function of temperature, illumination wavelength, the area of active zone of the PV cell, and the mobility of the electrons. Also, we can characterize the cell by the voltage between the cell electrodes in the case of no charge in the output of the cell, $\mathrm{V}_{\text {co }}$. It is a function of cell type, illumination wavelength, the material of active zone of the cell, and the type of contact between the active layer and the electrodes. In addition, the efficiency ratio of power, $\mathfrak{y}$, can also characterize the PV cell. It is defined by $[18,19]$ :

$$
\mathfrak{y}=\frac{P_{\max }}{P_{\text {in }}}
$$

where $P_{\max }$ represents the maximum power delivered by the cell and $P_{\text {in }}$ represents the incident power to the area of the cell.
Our proposed model is based on various electric characterizations of each element that are presented in Figure 1. Figure 2 illustrates the proposed model. The leakage current, presented by the resistance $R_{p}$, is in series with the diode of connection. It is clear that the current delivered by the cell is augmented by the Ip term that represents the leakage current. The leakage $R_{p}$ can be carefully varied in the phase of construction. Thus, if his value is augmented, the current delivered to the charge is augmented and so the power.

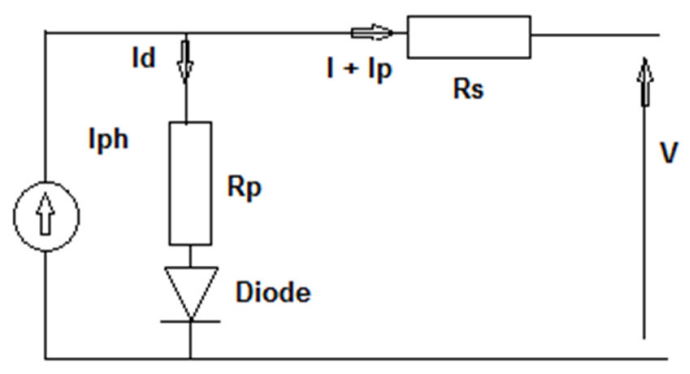

Fig. 2. The proposed model.

The current delivered by the proposed cell is:

$$
I_{p v}=I_{p h}-I_{s}\left(e^{\frac{v_{p v}+I_{p v} \cdot R_{s}}{v_{t} \cdot n}}-1\right)+\frac{V_{p v}+I_{p v} \cdot R_{s}}{R_{p}}
$$

The photonic current of the PV cell depends directly on the solar illumination and on the variation of the temperature. The following expression gives the photonic current [18]:

$$
\mathrm{I}_{\mathrm{ph}}=\frac{\mathrm{G}}{\mathrm{G}_{\mathrm{ref}}}\left(\mathrm{I}_{\mathrm{ph}_{\mathrm{ref}}}-\mathrm{k}_{\mathrm{i}}\left(\mathrm{T}_{\mathrm{c}}-\mathrm{T}_{\mathrm{c}_{\mathrm{ref}}}\right)\right)
$$

where $\mathrm{I}_{\mathrm{ph} \_ \text {ref }}$ is the photonic current under reference condition, $\mathrm{k}_{\mathrm{i}}$ is the current sensitivity coefficient for the temperature, $\mathrm{G}$ is the real illumination, $G_{r e f}$ is the illumination under the reference condition, $\mathrm{T}_{\mathrm{c}}$ is the real cell temperature, and $\mathrm{T}_{\mathrm{c}_{-} \text {ref }}$ is the cell temperature under the reference condition.

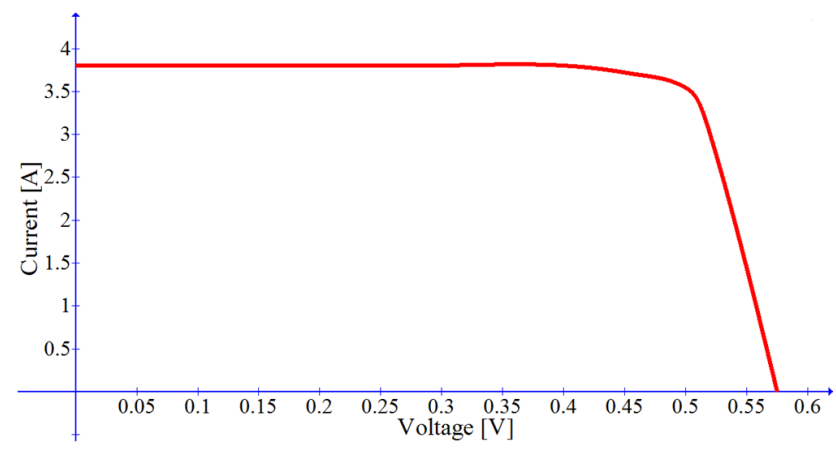

Fig. 3. Current- Output Voltage characteristic of the proposed model.

Figure 3 represents the Current-Output Voltage characteristic and Figure 4 represents the Power-Output Voltage characteristic of the proposed model under standard conditions: $1000 \mathrm{~W} / \mathrm{m}^{2}$ illumination and $20^{\circ} \mathrm{C}$ temperature. The presented curves are similar with the results published 
previously in this field $[5,8,10]$. The characteristics of our model are summarized in Table II. The obtained results are similar with the results in $[10,13,16]$.

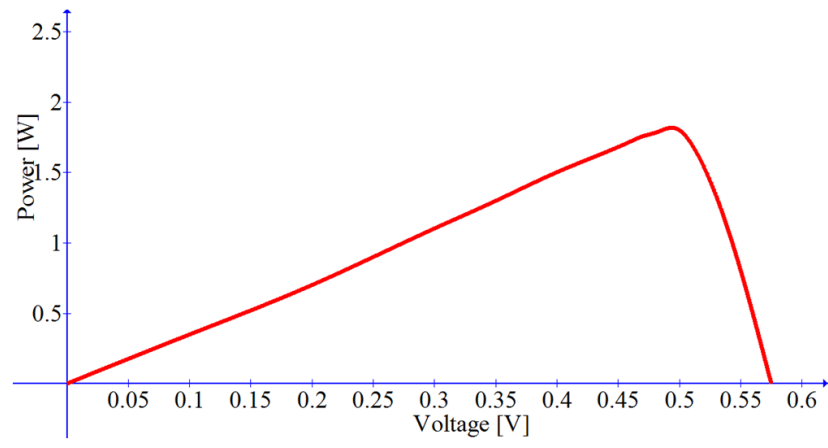

Fig. 4. Power - Output Voltage characteristic of the proposed model.

TABLE II. CHARACTERISTICS OF THE PROPOSED MODEL

\begin{tabular}{|c|c|}
\hline Characteristic & Value \\
\hline Open circuit voltage (V) & 0.575 \\
\hline Short circuit current (A) & 3.8 \\
\hline Voltage at maximum power (V) & 0.5 \\
\hline Current at maximum power (A) & 3.6 \\
\hline Cells & 1 \\
\hline
\end{tabular}

\section{CHARACTERISTICS OF THE PV CELL UNDER VARIATIONS} OF TEMPERATURE AND ILLUMINATION

Temperature is a very important characteristic in the PV cell behavior. Figures 5 and 6 present the influence of the temperature in the Current - Output Voltage and Power Output Voltage characteristics under fixed illumination of $1000 \mathrm{~W} / \mathrm{m}^{2}$. The curves show that the temperature negatively influences the open circuit voltage where the more the temperature increases the more the open circuit voltage decreases while the circuit current increases slightly. Thus, the maximum power of the PV cell undergoes a decrease when the temperature increases, which is confirmed in the curves of Figure 6.

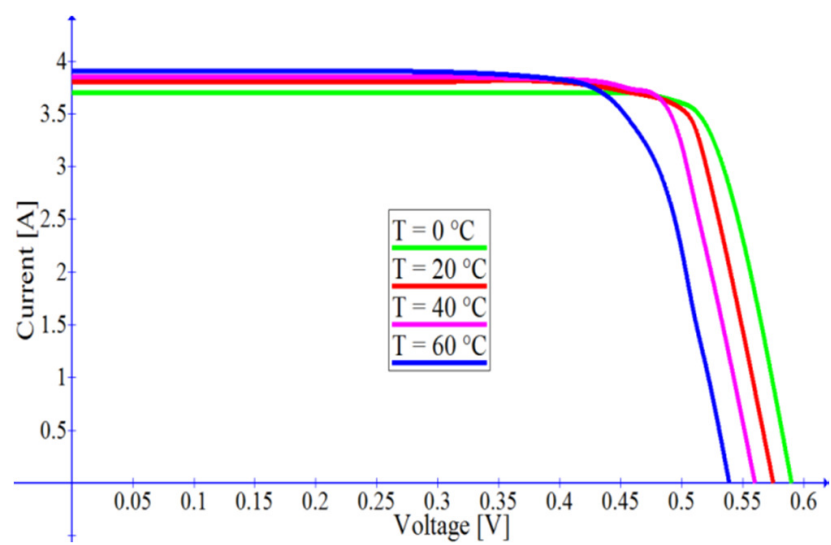

Fig. 5. Influence of the temperature on the Current - Output Voltage characteristics.

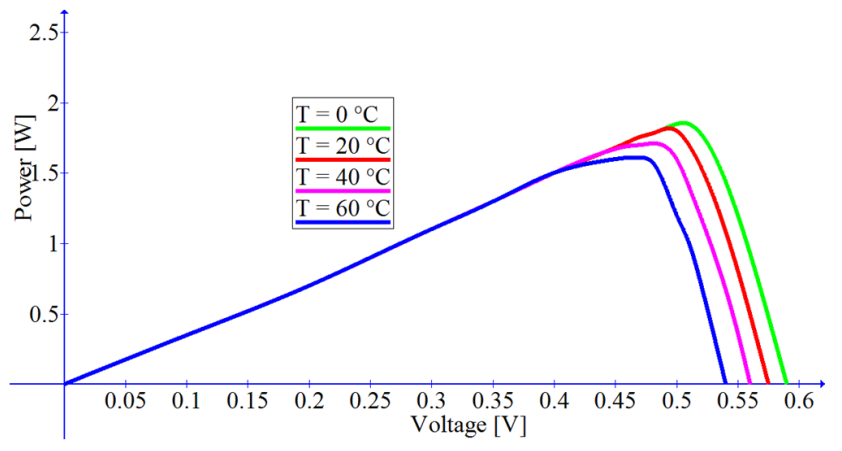

Fig. 6. Influence of the temperature on the Power - Output Voltage characteristics.

Figures 7 and 8 present the influence of the illumination in the Current - Output Voltage and Power - Output Voltage characteristics under a fixed temperature of $25^{\circ} \mathrm{C}$. From the curves, when the illumination varies for a given temperature, the current of the circuit varies in proportion to the illumination, and at the same time, the voltage varies very little. In addition, power increases when the illumination increases due to the rise in the current. Thus the results show that the MPP varies clearly with illumination.

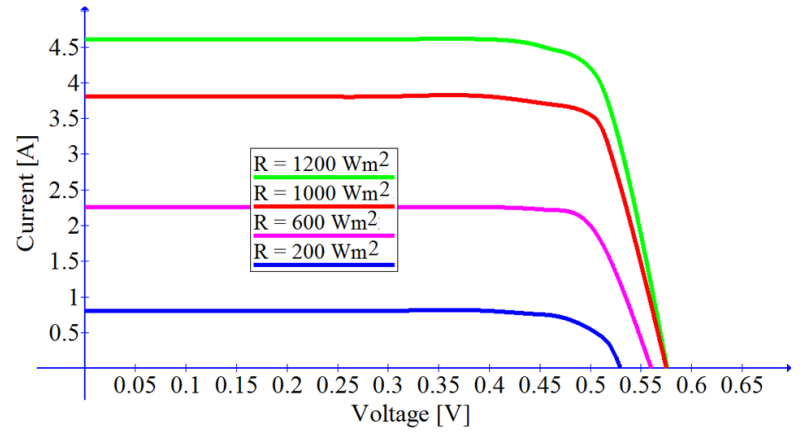

Fig. 7. Influence of the illumination on the Current - Output Voltage characteristics.

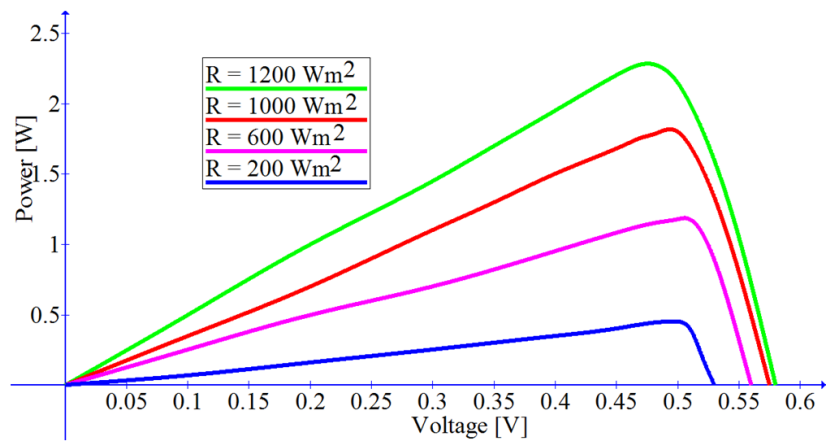

Fig. 8. Influence of the illumination on the Power - Output Voltage characteristics of the proposed model.

\section{CHARACTERISTICS OF THE PHOTOVOLTAIC CELL UNDER VARIATIONS OF MODEL RESISTANCES}

Figures 9 and 10 present the influence of the serial resistance $R_{s}$ in the Current - Output Voltage and Power Output Voltage characteristics. This resistance acts on the slope 
of the Current - Output Voltage characteristic but does not modify the output open circuit voltage and slightly decreases the circuit current value. However, the increase in the resistance value results in a decrease in the slope of the power curve and the values of the MPP.

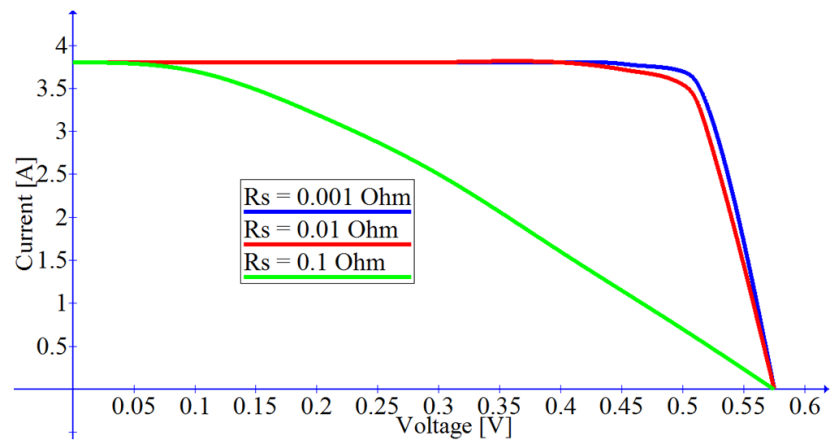

Fig. 9. Influence of the serial resistance $R_{s}$ on the Current - Output Voltage characteristics of the proposed model.

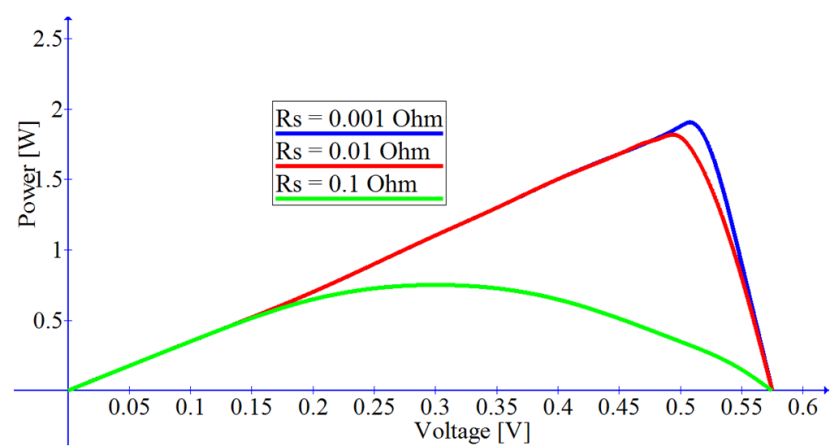

Fig. 10. Influence of the serial resistance $\mathrm{R}_{\mathrm{s}}$ on the Power - Output Voltage characteristics of the proposed model.

The resistance $R_{p}$ takes into account the inevitable leaks of the current which occur between the terminals of the solar cell. This resistance has a high value, andits effect is mainly in the current generation part. It is for this reason that we put this resistance in series with the diode instead of putting it in parallel in our proposed model.

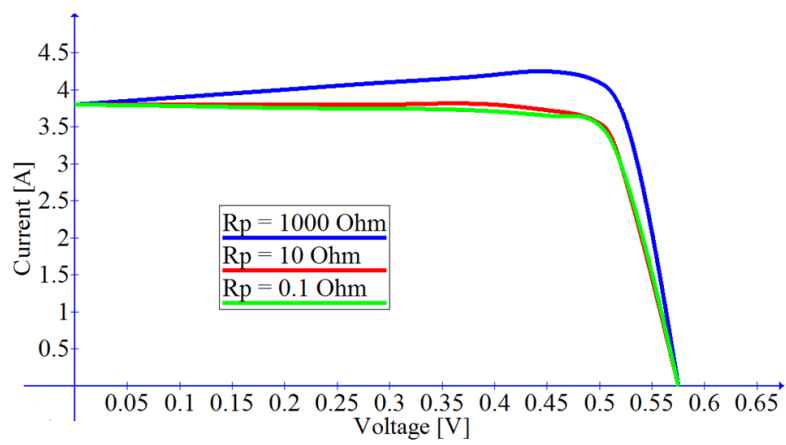

Fig. 11. Influence of the current leakage resistance $R_{p}$ on the Current Output Voltage characteristics of the proposed model.

Figures 11 and 12 present the influence of the leakage current resistance $R_{p}$ in the characteristics Current - Output
Voltage and Power - Output Voltage. In the normal case, the influence of the parallel resistance on the Current - Output Voltage characteristic results in a slight decrease in the open circuit voltage and a decrease in the slope. In addition, the power supplied by the solar cell varies with this parallel resistance, the more this high resistance, the more important the supplied power. For our model, the simulation results confirm those mentioned above for a normal model. However, it is very clear from Figure 12 that we have increased the MPP, which is very important for a solar cell generator and is a clear advantage of the proposed model.

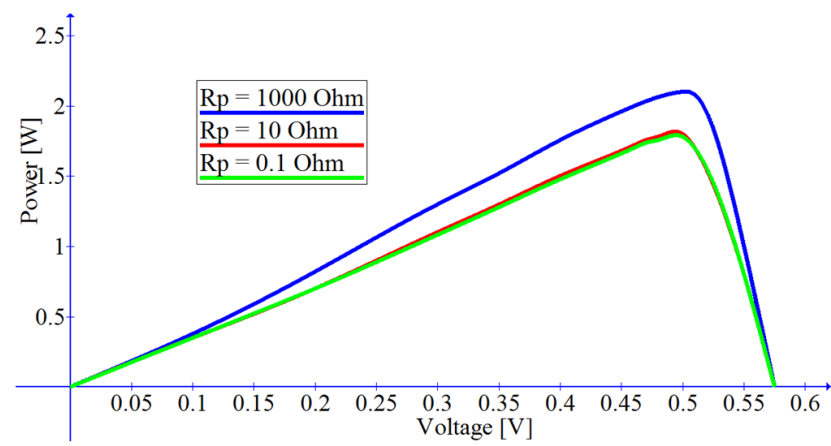

Fig. 12. Influence of the current leakage resistance $R_{p}$ on the Power Output Voltage characteristics of the proposed model.

\section{THE MPPT ALGORITHM}

This part demonstrates the algorithm that provides in each instance the maximum power delivered from the PV cell. Maximum power means finding the MPP of the proposed model. This method is named MPPT (Maximum Power Point Tracking). In this part, a command that can find this MPP is demonstrated. Figure 13 represents the MPP position delivered by the PV cell under variations of illumination and fixed temperature of $25^{\circ} \mathrm{C}$. In addition, in order to assure that the solar cell operates at its MPP, controllers are utilized to minimize the error between the operating power and the maximum variable reference power based on optimal methods and depending on climatic conditions. Figure 14 presents the principal of our MPPT command. The used circuit is that of a tunable edge filter based on a microcontroller system. The purpose is to give maximum power without fluctuations. The organigram algorithm of the command MPP is given in Figure 15.

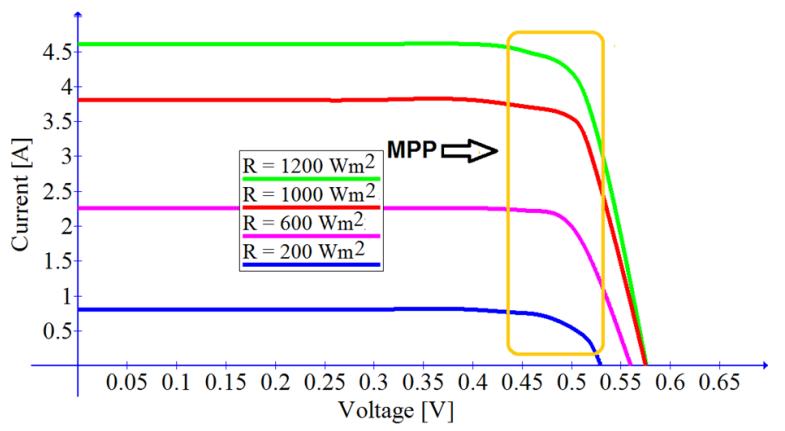

Fig. 13. MPP position in the characteristics of the PV cell under illumination variation and $25^{\circ} \mathrm{C}$. 


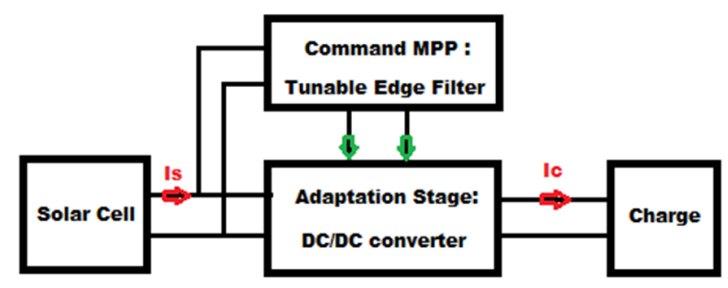

Fig. 14. Command MPP, tunable Edge filter, in the PV generator: cell and charge.

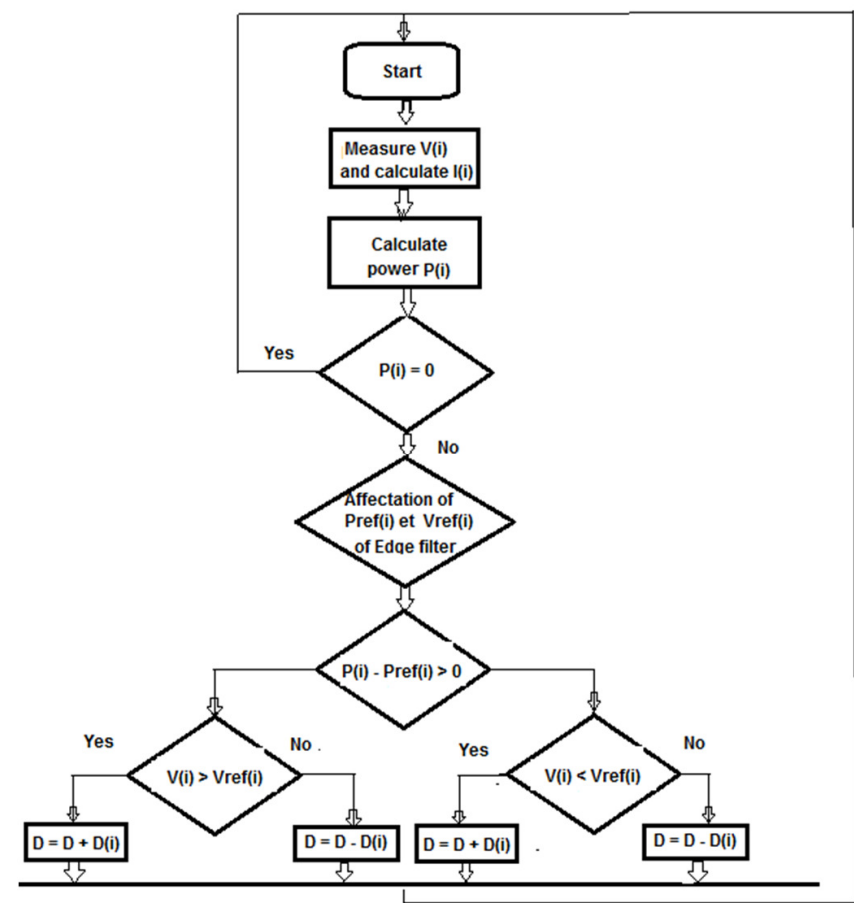

Fig. 15. Organigram algorithm of the MPP command using a tunable Edge filter.

For our MPP command and tunable Edge filter, the evolution of the power is analyzed after each voltage or current fluctuation. Thus, we measure the voltage and we calculate the current. After that, we calculate the power delivered by the solar cell at each tunable time interval according to the variation of lighting and the temperature. The basis of our electronic tunable edge filter is a PIC16F877A microcontroller, an optocoupler, a NAND logic component, a high and low side driver for external N-Channel MOSFET, and an N-channel MOSFET. The last component is used to control the adaptation stage in order to reach the MPP, see Figure 17.

The reasoning is that we have a power value and we measure the new value. The difference between the two values must lie between the maximum edge and the minimum edge of the tunable filter represented by $\mathrm{P}_{\text {ref }}(\mathrm{i})$ and $\mathrm{V}_{\text {ref }}(\mathrm{i})$. This edge is defined in the microcontroller program each time. Once the value is determined and meets the criteria of the tunable filter, the MOSFET becomes busy in the adaptation stage and thus we have a maximum of power which is delivered to the load according to the duty cycle D. The simulation of our MPP command and the adaptation stage for different values of illumination under a constant temperature of $25^{\circ} \mathrm{C}$ is given in Figure 16. This Figure shows that the power is stable for a determined period for a constant value of illumination. Table III resumes the characteristic of our MPPT and shows the comparison with other methods that are presented in [20]. From the result, we can say that our proposed MPPT is practical and efficient in acquiring the MPP and controlling the DC/DC converter to the load. As an example of the usefulness of the proposed scheme and its encouraging results, it may be used to improve the use of the PV technology in hybrid vehicles [21].

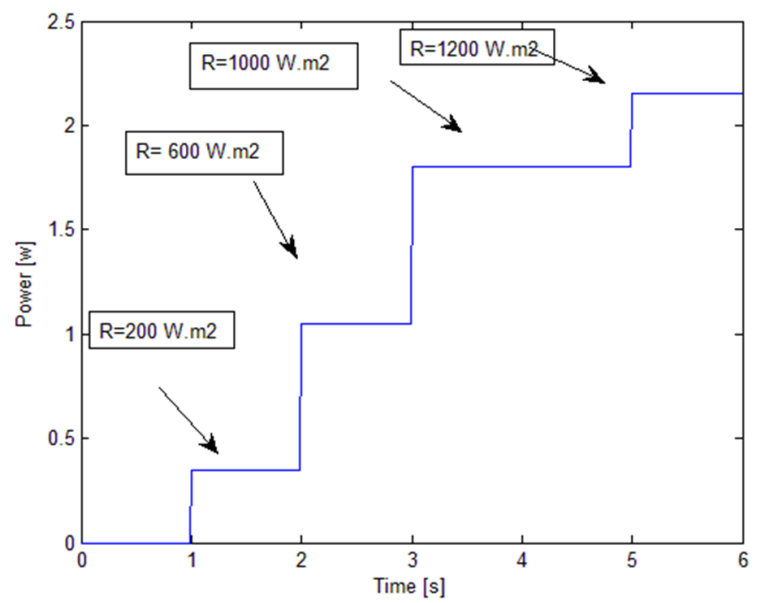

Fig. 16. Illustration of the power delivered to the charge after the determination of the MPP with the tunable edge filter.

TABLE III. COMPARISON OF MPPT TECHNIQUES

\begin{tabular}{|c|c|c|c|c|}
\hline $\begin{array}{c}\text { MPPT } \\
\text { Technique }\end{array}$ & $\begin{array}{c}\text { Tunable } \\
\text { Edge } \\
\text { Filter }\end{array}$ & P \& O & $\begin{array}{c}\text { Incremental } \\
\text { Conductance } \\
\text { Perturbation }\end{array}$ & $\begin{array}{c}\text { Neural } \\
\text { Network }\end{array}$ \\
\hline $\begin{array}{c}\text { Type of sensor } \\
\text { used }\end{array}$ & Voltage & $\begin{array}{c}\text { Voltage } \\
\text { and } \\
\text { current }\end{array}$ & Voltage and current & $\begin{array}{c}\text { Voltage } \\
\text { and current }\end{array}$ \\
\hline $\begin{array}{c}\text { Identification of } \\
\text { PV panel } \\
\text { parameters }\end{array}$ & No & No & No & Yes \\
\hline Complexity & Low & Low & Average & High \\
\hline Precision & $96 \%$ & $95 \%$ & $98 \%$ & $99 \%$ \\
\hline
\end{tabular}

\section{CONCLUSION}

A new PV cell model was presented in this paper. The obtained results confirm the results of published previous works. The new model was subjected to temperature, illumination, and serial and leakage resistance variations. The influence of the position of the leakage variation in our model shows that our model can give more power. In addition, a MPPT command was presented. The command is an electronic tunable filter using a microcontroller system. The simulation results show that the proposed command is efficient in determining the MPP. 


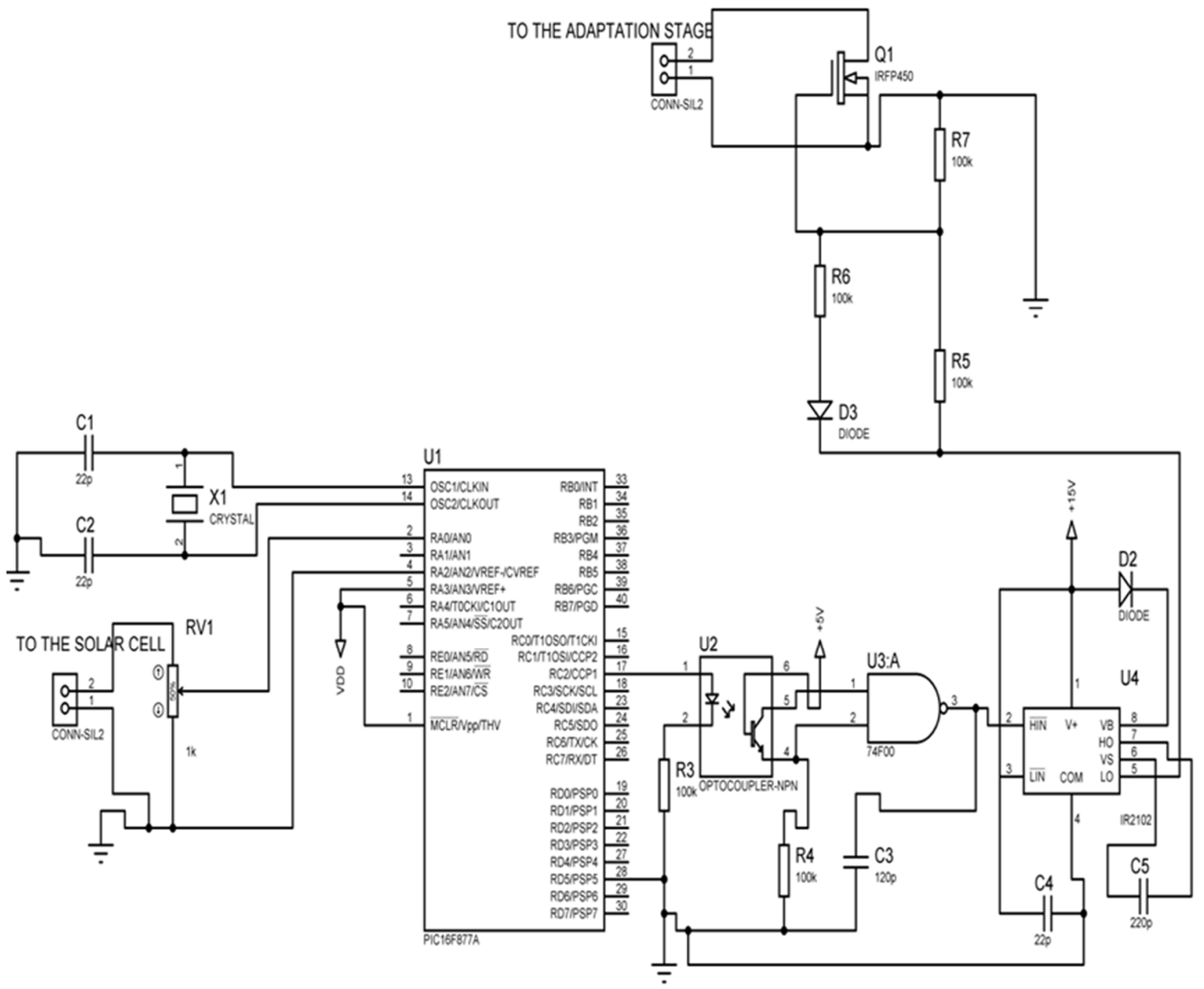

Fig. 17. The electronic tunable edge filter for the MPP command.

\section{REFERENCES}

[1] K. Kassmi, M. Hamdaoui, and F. Olivié, "Conception et modélisation d'un système photovoltaïque adapté par une commande MPPT analogique," Revue des Energies Renouvelables, vol. 10, no. 4, pp. 451462, 2007.

[2] H. Rezk and E.-S. Hasaneen, "A new MATLAB/Simulink model of triple-junction solar cell and MPPT based on artificial neural networks for photovoltaic energy systems," Ain Shams Engineering Journal, vol. 6, no. 3, pp. 873-881, Sep. 2015, https://doi.org/10.1016/j.asej. 2015.03.001.

[3] Y. Cheddadi, F. Errahimi, and N. Es-sbai, "Design and verification of photovoltaic MPPT algorithm as an automotive-based embedded software," Solar Energy, vol. 171, pp. 414-425, Sep. 2018, https://doi.org/10.1016/j.solener.2018.06.085.

[4] N. Pandiarajan, R. Ramaprabha, and R. Muthu, "Application of Circuit Model for Photovoltaic Energy Conversion System," International Journal of Photoenergy, vol. 2012, Mar. 2012, Art. no. e410401, https://doi.org/10.1155/2012/410401.

[5] H. Attoui, F. Khaber, M. Mustapha, K. Kassmi, and N. Essounbouli, "Development and experimentation of a new MPPT synergetic control for photovoltaic systems," Journal of Optoelectronics and Advanced Materials, vol. 18, no. 1-2, pp. 165-173, Jan. 2016.

[6] S. L. Brunton, C. W. Rowley, S. R. Kulkarni, and C. Clarkson, "Maximum Power Point Tracking for Photovoltaic Optimization Using Ripple-Based Extremum Seeking Control," IEEE Transactions on Power Electronics, vol. 25, no. 10, pp. 2531-2540, Oct. 2010, https://doi.org/10.1109/TPEL.2010.2049747.
[7] M. A. Sahnoun, H. M. R. Ugalde, J.-C. Carmona, and J. Gomand, "Maximum Power point Tracking Using P\&O Control Optimized by a Neural Network Approach: A Good Compromise between Accuracy and Complexity," Energy Procedia, vol. 42, pp. 650-659, Jan. 2013, https://doi.org/10.1016/j.egypro.2013.11.067.

[8] G. Hong-Wei, D. Wen-Li, Q. Feng, and W. Lu, "A Dissimilation Particle Swarm Optimization-Based Elman Network and Applications for Identifying and Controlling Ultrasonic Motors," in Analysis and Design of Intelligent Systems using Soft Computing Techniques, P. Melin, O. Castillo, E. G. Ramírez, J. Kacprzyk, and W. Pedrycz, Eds. Berlin, Heidelberg, Germany: Springer, 2007, pp. 397-407.

[9] C.-S. Chiu, "T-S Fuzzy Maximum Power Point Tracking Control of Solar Power Generation Systems," IEEE Transactions on Energy Conversion, vol. 25, no. 4, pp. 1123-1132, Dec. 2010, https://doi.org/10. 1109/TEC.2010.2041551.

[10] J. Ahmed and Z. Salam, "An improved perturb and observe (P\&O) maximum power point tracking (MPPT) algorithm for higher efficiency," Applied Energy, vol. 150, pp. 97-108, Jul. 2015, https://doi.org/10.1016/j.apenergy.2015.04.006.

[11] M. Birane, A. Derrouazin, M. Aillerie, A. Cheknane, and C. Larbes, "Evaluation and Performance of Different topologies of converters with Efficient MPPT in a Photovoltaic System - ProQuest," Journal of Electrical Systems, vol. 16, no. 3, pp. 308-319, 2008.

[12] S. Li, H. Liao, H. Yuan, Q. Ai, and K. Chen, "A MPPT strategy with variable weather parameters through analyzing the effect of the DC/DC converter to the MPP of PV system," Solar Energy, vol. 144, pp. 175184, Mar. 2017, https://doi.org/10.1016/j.solener.2017.01.002.

[13] D. Sera, L. Mathe, T. Kerekes, S. V. Spataru, and R. Teodorescu, "On the Perturb-and-Observe and Incremental Conductance MPPT Methods 
for PV Systems," IEEE Journal of Photovoltaics, vol. 3, no. 3, pp. 1070 1078, Jul. 2013, https://doi.org/10.1109/JPHOTOV.2013.2261118.

[14] T. V. Krishna, M. K. Maharana, and C. K. Panigrahi, "Integrated Design and Control of Renewable Energy Sources for Energy Management," Engineering, Technology \& Applied Science Research, vol. 10, no. 3, pp. 5857-5863, Jun. 2020, https://doi.org/10.48084/etasr.3613.

[15] D. Rekioua and E. Matagne, Optimization of Photovoltaic Power Systems: Modelization, Simulation and Control. London, UK: SpringerVerlag, 2012.

[16] H.-L. Tsai, T. Ci-Siang, and S. Yi-Jie, "Development of generalized photovoltaic model using MATLAB/SIMULINK," in Proceedings of the World Congress on Engineering and Computer Science 2008, San Francisco, USA, Oct. 2008.

[17] A. Acakpovi and E. B. Hagan, "Novel Photovoltaic Module Modeling using Matlab/Simulink," International Journal of Computer Applications, vol. 83, no. 16, pp. 27-32, Dec. 2013, https://doi.org/ 10.5120/14535-2978.

[18] T. T. Guingane, Z. Koalaga, E. Simonguy, F. Zougmore, and D. Bonkoungou, "Modélisation et simulation d'un champ photovoltaïque utilisant un convertisseur élévateur de tension (boost) avec le logiciel MATLAB /SIMULINK.," Journal International de Technologie, de l'Innovation, de la Physique, de l'Energie et de l'Environnement, vol. 2, no. 1, 2016, https://doi.org/10.18145/jitipee.v1i2.80.g59.

[19] T. Bouguerra, "Optimisation d'un système photovoltaïque : Application en continu et en alternatif," M.S. thesis, Université Mentouri de Constantine 1, Constantine, Algeria, 2014.

[20] H. Abbes, H. Abid, K. Loukil, A. Toumi, and M. Abid, "Etude comparative de cinq algorithmes de commande MPPT pour un système photovoltaïque," Revue des Energies Renouvelable, vol. 17, no. 3, pp. 435-445, 2014.

[21] M. E. Bendib and A. Mekias, "Solar Panel and Wireless Power Transmission System as a Smart Grid for Electric Vehicles," Engineering, Technology \& Applied Science Research, vol. 10, no. 3, pp. 5683-5688, Jun. 2020, https://doi.org/10.48084/etasr.3473. 